\title{
Effect of a Wildlife-Livestock Interface on the Prevalence of Intra-Erythrocytic Hemoparasites in Cattle
}

\author{
Richard M. Kabuusu ${ }^{1,2 *}$, Ruth Alexander ${ }^{1}$, Annet M. Kabuusu' ${ }^{2}$, Sylvia N. Muwanga ${ }^{3}$, \\ Patrick Atimnedi ${ }^{4}$, Calum Macpherson ${ }^{2,5}$ \\ ${ }^{1}$ Pathobiology Academic Program St. George’s Grenada, School of Veterinary Medicine, \\ St. George's University, St. George’s, Grenada \\ ${ }^{2}$ Graduate Studies Program, St. George’s University, St. George’s, Grenada \\ ${ }^{3}$ Department of Wildlife and Animal Resources Management, Faculty of Veterinary Medicine, \\ Makerere University, Kampala, Uganda \\ ${ }^{4}$ Uganda Wildlife Authority (UWA), Kampala, Uganda \\ ${ }^{5}$ School of Medicine, St. George’s University, St. George’s, Grenada \\ Email: *rkabuusu@sgu.edu
}

Received October 22, 2013; revised November 22, 2013; accepted November 29, 2013

Copyright (C 2013 Richard M. Kabuusu et al. This is an open access article distributed under the Creative Commons Attribution License, which permits unrestricted use, distribution, and reproduction in any medium, provided the original work is properly cited. In accordance of the Creative Commons Attribution License all Copyrights (c) 2013 are reserved for SCIRP and the owner of the intellectual property Richard M. Kabuusu et al. All Copyright (C) 2013 are guarded by law and by SCIRP as a guardian.

\begin{abstract}
We conducted a cross-sectional study to establish the effect of proximity of livestock to a wildlife-livestock interface on the relative abundance of intra-erythrocytic hemoparasites in cattle. Blood samples were obtained from 131 randomlyselected cattle raised around Queen Elizabeth National Park. Cattle-farm location was determined by using Global Positioning System device from an arbitrarily reference point. Giemsa-stained blood smears were examined microscopically for intra-erythrocytic hemoparasites. Correlational analysis was used to examine the relationship between farm location and prevalence, whereas risk ratios were used to determine the strength of mixed hemoparasitic infections among cattle, using a significant level of $\alpha=0.05$. The location of a cattle farm significantly predicted the prevalence of Anaplasma ( $\mathrm{rs}=0.33, \mathrm{p}<0.05$ ) and Theileria ( $\mathrm{rs}=0.57, \mathrm{p}<0.01$ ) but, farm's proximity to QENP did not explain the variation in the prevalence of Babesia ( $\mathrm{rs}=0.14, \mathrm{p}<0.2$ ). Although mixed infections occurred in $15 \%$ of sampled cattle, concurrent infection of cattle with A. marginale and B. bigemina [RR = 36; 95\% CI (7.191); $<<0.001$ ] was the only statistically significant mixed infection which was recorded. This study demonstrated that unlike the prevalence of $B$. bigemina, the prevalence of $T$. parva and A. marginale in livestock significantly increased with close proximity to a wildlife-livestock interface.
\end{abstract}

Keywords: Wildlife-Livestock Interface; Geographical Information System; Proximity; Ankole Long-Horned Cattle; Intra-Erythrocytic Hemoparasites

\section{Introduction}

Wildlife-livestock interfaces are characterized by conflict between livestock keepers and wildlife conservation authorities especially as it relates to the transmission and prevention of diseases common to both wildlife and domesticated animals [1].

Livestock keepers living within the wildlife-livestock interface mostly practice pastoral farming as a sustainable management system [2]. This management system is characterized by bidirectional movement of domesticated

"Corresponding author. cattle and wild herbivores in search of water and pasture with little regard to defined boundaries, limited access to veterinary services, use of local plant species for prophylaxis and chemotherapy, and if inadequate at all any record keeping [2,3]. Such characteristics of the wildlifelivestock interface are fundamentally responsible for patterns of distribution of ticks and tick borne diseases (TTBDs) between livestock and wildlife [2,4]. Cattle keepers raising animals around wildlife national parks have identified Theileriosis (East coast fever) caused by Theileria parva and vectored by Rhepicephalus appendiculatus; Anaplasmosis caused by Anaplasma margi- 
nale and vectored by $R$. evertsi evertsi and Babesiosis (Red water) caused by Babesia bigemina and vectored by Boophilus decoloratus as priority diseases [3,5-7].

In an effort to find solutions to conflicts which occur as a result of these diseases, as well as to better understand the effect of the wildlife-livestock interface on the transmission dynamics of intra-erythrocytic hemoparasites, Ankole-long horned cattle raised around Queen Elizabeth National Park (QENP) were sampled and tested with the aim of investigating whether proximity of livestock to a wildlife-livestock influenced the relative abundance of intra-erythrocytic hemoparasites. Nonintra-erythrocytic hemoparasites are beyond the scope of this study.

\section{Materials and Methods}

\subsection{Study Area and Design}

With permission from the Uganda Wildlife Authority (UWA) and Uganda National Council for Science and Technology, a cross sectional survey was performed around QENP between June, 2005 and March, 2006. QENP covers an area of over $2000 \mathrm{sq} \mathrm{km}$ and lies in the Western region of Uganda $\left(0^{\circ} 23^{\prime} \mathrm{S}\right.$ Latitude $29^{\circ} 58^{\prime} \mathrm{E}$ Longitude). Katunguru Bridge was arbitrarily selected a reference point and farms located east to this point were included in the study. Geographical information system (GIS) coordinates of the kraal were taken for each farm using a global positioning system (GPS) device (Garmin eTrex $^{\circledR}$ Legend C). Inclusion criteria considered farms with 10 - 30 indigenous Ankole long-horned cows aged between 1 month and 7 years. Cattle with evidence of clinical disease were excluded from the study but, appropriate treatment protocols with anti-protozoa agents were instituted. Because of confidentiality concerns, as well as the purpose of the study, all farms were coded with unique identification numbers.

\subsection{Sampling and Sample Size Determination}

An established prevalence (10\%) of mixed hemoparasite infection in adult cattle [8] and a $20 \%$ tolerable error were assumed when determining the number of cows to be randomly selected into the study [9]. About $3 \mathrm{mls}$ of blood were obtained by venipuncture of the jugular or tail veins of each cow sampled and placed in EDTA (Becton-Dickinson, vacutainer system, USA), labeled and stored at $6^{\circ} \mathrm{C}$ until further processing. Thin blood smear were prepared and stained with May-GrunwaldGiemsa and microscopically examined under oil immersion.

\subsection{Data Analysis}

Cattle were classified as positive or negative for intra- erythrocytic hemoparasites based on microscopic evaluation of the blood smear. Data were coded and statistical analyses were performed using EPIINFO (version 7, CDC, Georgia, Atlanta USA) at a significant level of $\alpha=$ 0.05 . We used a Spearman's rank correlation co-efficient to test for the effect of livestock proximity to a wildlifelivestock interface and risk ratio (RR) to determine the strengths of associations of mixed infection. Distances from the reference point, Katunguru Bridge, determined by GIS coordinates was calculated using GIS Arc View 3.2a.

$$
\begin{aligned}
& \text { Prevalence }=\frac{\text { No of animals with parasite }}{\text { Total number of animals sampled }} \times 100 \\
& \mathrm{RDP}=\frac{\text { Number of } \text { specific parasite }}{\text { Total number of parasites identified }} \times 100 \\
& \text { RDP: Relative diagnostic percentage. }
\end{aligned}
$$

\section{Results}

The target population was 139 cows but, blood samples were randomly obtained from only 131 cows located on 13 farms giving a response rate of 94.2\% (131/139). Failure to collect blood samples from 8 cows was due to a lack of adequate handling facilities. The nearest farm was 2.7 miles whereas farthest farm included in the study was 20.8 miles away the reference point. The prevalence of all intra-erythrocytic hemoparasite infections combined was 55.7\% (73/131) with varying between-farm prevalence (Table 1).

The prevalence of $T$. parva and A. marginale increased significantly with close proximity of livestock to the wildlife-livestock interface $\left(\mathrm{r}_{\mathrm{s}}=0.57, \mathrm{p}<0.01\right)$ and $\left(\mathrm{r}_{\mathrm{s}}=\right.$ $0.33, \mathrm{p}<0.05$ ) respectively but, the prevalence of Babesia did not vary significantly with closeness to the wildlife-livestock interface $\left(r_{s}=0.14, p=0.2\right)$. Mixed intraerythrocytic hemoprotozoan infections were detected in $15 \%(11 / 73)$ of cows and the number of hemoparasites identified ranged from 0 - 3 per cow but, the only statistically significant mixed infection was recorded between A. marginale and B. bigemina $[\mathrm{RR}=36 ; 95 \%$ CI (7.191); $\mathrm{p}<0.001$ ] (Table 2).

\section{Discussion}

This study is unique that it utilized proximity of the indigenous Ankole long-horned breed of cattle to QENP as a model for investigating the consequences of increasing interaction of domestic cattle with wildlife on the distribution of intra-erythrocytic hemoparasites in cattle.

In spite of the fact that intra-erythrocytic hemoparasites routinely cause fatal disease in cows [10] and that their prevalence was high, the cows used in this present study did not have evidence of clinical disease. This 
Table 1. Prevalence (\%) of intra-erythrocytic hemoparasites in cattle stratified by farm proximity.

\begin{tabular}{|c|c|c|c|c|c|}
\hline \multirow[b]{2}{*}{ Farm i.d } & \multirow[b]{2}{*}{ n } & \multirow[b]{2}{*}{$\begin{array}{c}\text { Distance } \\
\text { (miles) }\end{array}$} & \multicolumn{3}{|c|}{ Prevalence \% (95\% CI) } \\
\hline & & & T. parva & A. marginale & B. bigemina \\
\hline 1 & 11 & 2.7 & $55(23,83)$ & $36(11,69)$ & $9(0,41)$ \\
\hline 2 & 9 & 3.9 & $89(52,99)$ & $0(0,36)$ & $0(0,34)$ \\
\hline 3 & 10 & 4.8 & $60(26,88)$ & $60(26,88)$ & $10(0,45)$ \\
\hline 4 & 9 & 6.0 & $78(40,97)$ & $22(3,60)$ & $11(0,49)$ \\
\hline 5 & 11 & 7.1 & $73(39,94)$ & $9(0,41)$ & $22(3,52)$ \\
\hline 6 & 9 & 7.8 & $78(40,97)$ & $22(3,60)$ & $22(3,60)$ \\
\hline 7 & 9 & 9.0 & $11(0,11)$ & $11(0,48)$ & $0(0,37)$ \\
\hline 8 & 10 & 10.6 & $50(19,81)$ & $0(0,31)$ & $0(0,31)$ \\
\hline 9 & 10 & 11.5 & $40(26,87)$ & $20(3,57)$ & $10(0,44)$ \\
\hline 10 & 11 & 12.4 & $64(31,89)$ & $18(2,51)$ & $18(0,31)$ \\
\hline 11 & 10 & 14.6 & $0(0,31)$ & $0(0,31)$ & $0(0,29)$ \\
\hline 12 & 11 & 18.3 & $18(3,52)$ & $0(0,29)$ & $0(0,29)$ \\
\hline 13 & 11 & 20.8 & $0(0,29)$ & $0(0,29)$ & $0(0,29)$ \\
\hline
\end{tabular}

i.d = identification; $\mathrm{n}=$ number of cows sampled.

Table 2. Overall prevalence and relative diagnostic percent of intra-erythrocytic hemoparasites.

\begin{tabular}{ccc}
\hline & Prevalence 95\% CI & $\begin{array}{c}\text { Relative diagnostic } \\
\text { percent \% }\end{array}$ \\
\hline Theileria parva & $51 \%(95 \%$ CI 49, 62); & $68 \%(66 / 97)$ \\
Anaplasma marginale & $15 \%(95 \%$ CI 9, 21) & $21 \%(20 / 97)$ \\
Babesia bigemina & $8 \%(95 \%$ CI 4, 15) & $11 \%(11 / 97)$ \\
\hline
\end{tabular}

finding indicates that this indigenous cattle breed has adapted mechanisms to regulate the growth and development of hemoprotozoa in their blood which has led to endemic stability [11]. This desirable characteristic makes the Ankole long-horned breed apt for mixed livestockwildlife production systems; hence it lessens some of the conflicts in this wildlife-livestock interface.

With the highest prevalence and highest relative frequency of detection (RDP), T. parva appears to be of primary importance within the QENP wildlife-livestock interface. This suggests that wildlife, especially the Cape buffalo, which is a keystone species in QENP, is a natural reservoir, and therefore a fundamental source of vectors and hemoparasites for cattle [12].

$T$. parva and $A$. marginale infections were significantly higher in cattle raised closer to QENP wildlifelivestock interface. The zonal differences in prevalence may be directly correlated with the distribution of the specific vectors involved. Babesia bigemina had the lowest prevalence and proximity of cows to QENP was not significantly associated with the prevalence of $B$. bigemina in farmed cows. This finding is in accordance with previous research findings, which demonstrated that trends of $B$. bigemina across different ecological zones were similar [13]. Mixed A. marginale and B. bigemina infections were common and statistically significant, and likewise a high farm prevalence of $A$. marginale was matched by a high farm prevalence of $B$. bigemina. Similar mechanisms of transmission or cross-transmission may be possible explanations for the coexistence of $A$. marginale, and B. bigemina in cows [8,14].

The effects of confounding factors such as use of acaricides (concentration and frequency of application) or the method of acaricide application (spraying versus dipping) was not assessed in this study. Future studies using serological and molecular diagnostic tools are encouraged and may be performed concurrently with hemoparasites in wildlife herbivores.

\section{Conclusion}

In conclusion, this study finds evidence that proximity of livestock to a wildlife-livestock interface explains a significant proportion of the variation in the prevalence of $T$. parva and $A$. marginale infection in cattle but, it does not explain the variation in the prevalence of $B$. bigemina infection in cattle.

\section{Acknowledgements}

The authors wish to thank Texas A\&M University, Minority Initiative for Research and Training (MIRT), St. George's University School of Veterinary Medicine, Windward Research and Education Foundation (WINDREF) for funding the research. We wish to thank Dr. Raymond Sis and Dr. Ludwig Siefert their assistance and support.

\section{REFERENCES}

[1] R. A. Kock, R. G. Bengis and J. Fischer, "Infectious Animal Diseases: The Wildlife/Livestock Interface," Revue Scientifique et Technique Office International des Epizooties, Vol. 21, No. 1, 2002, pp. 53-65.

[2] M. Ocaido, L. Siefert and J. Baranga, "Disease Surveillance in Mixed Livestock and Game Areas around Lake Mburo National Park in Uganda," South African Journal of Wildlife Research, Vol. 26, No. 4, 1996, pp. 133-135.

[3] R. M. Kabuusu, C. N. L. Macpherson, B. B. Bakamanume, S. N. Muwanga, P. Atimnedi, S. Kumthekar, J. Caldwell and S. Zaplinski, "Proximity of Cattle Farm to a Wildlife-Livestock Interface as a Predictor of Prevalence of Selected Hemoparasites in Farmed Cattle," Proceedings of $56^{\text {th }}$ American Association of Veterinary Parastologists Conference, St. Louis, 2011, p. 80.

[4] F. Wesonga, G. Orinda, G. Ngae and J. Grootenhuis, "Comparative Tick Counts on Game, Cattle and Sheep on a Working Game Ranch in Kenya," Tropical Animal Health and Production, Vol. 38, No. 1, 2006, pp. 35-42. http://dx.doi.org/10.1007/s11250-006-4318-3 
[5] J. Okello-Onen, E. M. Tukahirwa, B. D. Perry, G. J. Rowlands, S. M. Nagda, G. Musisi, E. Bode, R. Heinonen, W. Mwayi and J. Opuda-Asibo, "Population Dynamics of Ticks on Indigenouscattle in a Pastoral Dry to Semi-Arid Range and Zone of Uganda,” Experimental \& Applied Acarology, Vol. 23, No. 1, 1999, pp. 79-88. http://dx.doi.org/10.1023/A:1006058317111

[6] Z. I. Rajput, S.-H. Hu, A. G. Arijo, M. Habib and M. Khalid, "Comparative Study of Anaplasma Parasites in Tick Carrying Buffaloes and Cattle,” Journal of Zhejiang University Science B, Vol. 6, No. 11, 2005, pp. 10571062.

[7] F. Kabi, J. W. Mugona, G. W. Nasinyama and J. Walubengo, "Seroprevalence of Tick-Borne Infections among the Nkedi Zebu and Ankole Cattle in Soroti District, Uganda," Journal of Protozoology Research, Vol. 18, No. 2, 2008, pp. 61-70.

[8] J. W. Magona and J. S. P. Mayende, “Occurence of Concurrent Trypanosomosis, Theileriosis, Anaplasmosis and Helminthosis in Friesian, Zebu and Sahiwal Cattle in Uganda," Onderstepoort Journal of Veterinary Research, Vol. 69, No. 2, 2002, pp. 133-140.

[9] S. W. Martin, A. H. Meek and P. Willeberg, "Veterinary Epidemiology. Principles and Methods," Iowa State University Press, Ames, 1987.
[10] D. Shannon, "Field Cases of East Coast Fever in Grade Cattle in Uganda," Tropical Animal Health and Production, Vol. 9, No. 1, 1977, pp. 29-35. http://dx.doi.org/10.1007/BF02297388

[11] R. W. Paling, C. Mpagala, B. Luttinhuizen and G. Sibomana, "Exposure of Ankole Cattle and Crossbred Cattle to Theileriosis in Rwanda," Tropical Animal Health and Production, Vol. 23, No. 4, 1991, pp. 203-214. http://dx.doi.org/10.1007/BF02357101

[12] M. Ocaido, R. T. Muwazi and J. Opuda-Asibo, "Disease Incidence in Ranch and Pastoral Livestock Herds around Lake Mburo National Park, in South Western Uganda,” Tropical Animal Health and Production, Vol. 41, No. 7, 2009, pp. 1299-1308. http://dx.doi.org/10.1007/s11250-009-9315-x

[13] C. Rubaire-Akiiki, J. Okello-Onen, G. W. Nasinyama, M. Vaarst, E. K. Kabagambe, W. Mwayi, D. Musunga and W. Wandukwa, "The Prevalence of Serum Antibodies to TickBorne Infections in Mbale District, Uganda: The Effect of Agroecologicalzone, Grazing Management and Age of Cattle,” Journal of Insect Science, Vol. 4, No. 8, 2004, p. 8.

[14] C. P. Otim, "Advances in Disease Control: Ticks and TickBorne Diseases," Uganda Journal of Agricultural Sciences, Vol. 5, No. 1, 2000, pp. 79-85. 